\title{
Extending the Geopolitical Supply Risk Indicator: Application of Life Cycle Sustainability Assessment to the Petrochemical Supply Chain of Polyacrylonitrile-based Carbon Fibers
}

\author{
Christoph Helbig ${ }^{a}$, Eskinder D. Gemechu', Baptiste Pillain ${ }^{b}$, Steven B. Young ${ }^{c}$, Andrea Thorenz ${ }^{a}$, Axel Tuma ${ }^{\text {a }}$, Guido \\ Sonnemann ${ }^{\mathrm{b}, *}$ \\ *Address correspondence to: guido.sonnemann@u-bordeaux.fr \\ ${ }^{a}$ : Resource Lab, Institute of Materials Resource Management, University of Augsburg \\ Universitaetsstr. 16, 86159 Augsburg, Germany \\ ${ }^{\mathrm{b}}$ : The Life Cycle Group, Institute of Molecular Sciences, Université de Bordeaux, Bordeaux, France \\ ${ }^{c}$ : School of Environment, Enterprise and Development (SEED), University of Waterloo, Waterloo, Canada
}

Published in: Journal of Cleaner Production 137 (2016), 1170-1178.

https://doi.org/10.1016/j.jclepro.2016.07.214

\begin{abstract}
Due to the material diversity of high-tech products and globalized supply chains, it is important to be able to assess geopolitical supply risks for the supply chain of any commodity. This article extends the Geopolitical Supply Risk assessment method under the Life Cycle Sustainability Assessment framework to account for multi-stage supply chains as well as domestic production and applies this extended method to the supply chain of carbon fibers based on polyacrylonitrile. Particularly, the article estimates the Geopolitical Supply Risk factors emerging from international trade of petroleum, propene and acrylonitrile. Risk factors are calculated for 145 countries, and a total set of six scopedependent indicators is identified for 54 countries. The case studies of acrylonitrile supply chains for Russia, Peru, Japan and Greece exemplify this approach and risk mitigation strategies are discussed for each of them. The results show the applicability of the modified Geopolitical Supply Risk characterization factor to a multi-stage supply chain with different internationally traded commodities in the petrochemical industry. Thereby the method serves to further integrate Life Cycle Assessment and the socio-economic dimension of natural resource impacts.
\end{abstract}

\section{Keywords}

supply risk; life cycle sustainability assessment; criticality assessment; carbon fiber; political stability 


\section{Introduction}

Geopolitical interdependencies of nations and industries are inherent to globalized supply chains of modern high-tech products (Schaffartzik et al., 2014), which require a great number of raw materials (Greenfield and Graedel, 2013). The chemical and materials industries continually innovate new materials, necessitating a dynamic risk-evaluation (Krohns et al., 2011). Thus it is essential to consider abiotic and fossil resources efficiency in the development and installation of future technologies (Bradshaw et al., 2013). However, high grade and economical resources are extracted only in selected regions due to different geological, environmental and socio-economic circumstances (Craig et al., 2011). Raw material commodities are traded globally to satisfy highly specialized industries. There is often a mismatch between resource demand (especially from industrialized countries) and domestic production that is sometimes hidden (Johnson and Graedel, 2008). Resources can be of strategic relevance (Duan et al., 2015), they can be interlinked already at the extraction phase (Nassar et al., 2015), and their supply chain can be affected by serious risks (Nansai et al., 2015) including natural disasters, trade restrictions, armed conflicts or political instability. For metals and minerals, the concept of raw material criticality has brought up a set of indicators concerning supply risk, economic importance and environmental impacts (Graedel and Reck, 2015; Graedel et al., 2012; U.S. National Research Council, 2008), which can help identifying commodities and raw materials of highest importance or with a currently unsustainable metabolism. Implementing sustainability aspects of material use other than depletion of resources is an important step from classical life cycle assessment (LCA) to life cycle sustainability assessment (LCSA). Many of the missing considerations for a holistic LCSA concern the direct impact from the use of Natural Resources and may be addressed by considering criticality assessments (Sonnemann et al., 2015). For example, aspects can be geological risks (i.e., mining surplus costs (Vieira et al., 2016)), social risks (see S-LCA (Benoît et al., 2010)), but also geopolitical aspects, which emerge from international trade of raw materials, intermediates and finished products. These geopolitical aspects are the subject of this article. So far, different attempts have been made to bring concepts of resource criticality into the LCSA framework to better address resource sustainability challenges. Sonnemann et al. (2015) conducted an extensive review on the existing criticality assessment methods and provided a conceptual framework for integrating criticality into LCSA. Mancini et al. (2015b) and Drielsma et al. (2016) examine the role LCA can play in supporting the management of critical raw materials and help businesses and governments to assess their supply chains more systematically. However, the first modeling approach was provided by Schneider et al. (2014) who proposed a new framework for assessing resource competition by introducing economic elements (economic resource scarcity potential (ESP)) to the existing resource impact assessment, which was accompanied by an environmental scarcity potential (EnSP) and a social scarcity potential (SSP) (Schneider, 2014). Mancini et al. (2015a) also compared the relevance of LCA, Material Flow Analysis and resource criticality as a methodological tool for resources analysis in supporting policies within the European Union context. The three resource accounting methods have different approaches and focus on different objectives, therefore, the selection depends on the policy objectives. More recently Gemechu et al., (2015a) proposed a model to assess the geopolitical related supply risk under the LCSA framework, which was subsequently applied to an electric vehicle case study (Gemechu et al., 2015b). Nansai et al. (2015) recently developed a new footprint indicator, called mining risk footprint. 
This paper principally aims to advance upon the Geopolitical Supply Risk (GPSR) methodology of Gemechu et al., (2015a), to overcome some of its limitations and explicitly cover multiple supply chain stages. Applying it to a carbon fiber case study, the paper also aims at extending the applicability of the method from mineral resources to fossil fuels and demonstrating how the integration of resource criticality aspect with conventional LCA is possible. Securing reliable access to fossil fuel supplies has been a global political issue, especially when major sourcing countries are politically unstable, hence the same approach used for mineral resources can be applied to determining the supply risk of fossil fuels due to geopolitical aspects. Additionally, this paper suggests policy implications for businesses and other stakeholders involved in the supply chain of carbon fiber production: from petroleum (crude), to propene (also called propylene, $\mathrm{C}_{3} \mathrm{H}_{6}$ ), acrylonitrile (AN), polyacrylonitrile (PAN) precursor and eventually carbon fiber production. Carbon fiber is not listed as a "Critical Resource" in most resource criticality studies, which focus on nonfossil resources, mostly metals. Carbon fiber is, however, a material of strategic importance which has an anticipated increase in demand, thus needs a secure supply. For example, the US Department of Defense identified carbon fiber among the strategic and critical materials in which an insufficient supply to meet demand for defense use is foreseen (U.S. Department of Defense, 2013). The geopolitical concern over carbon fiber supply is principally due to technology concentration in the value chain: only a small number of chemical industries in the world have the technology to produce high-quality PAN precursor. Unlike most critical metals, which appear to have inherent supply restrictions at the mining stage of primary resource availability and have geopolitically relevant market concentrations at that stage (Habib et al., 2016), the bottleneck in the sustainable supply of carbon fiber lies mainly in an imbalance between the supply and demand of PAN. These industries need a reliable petrochemical supply chain.

The paper is structured into five sections. The second section describes the methodological ground on how to extend the Geopolitical Supply Risk assessment from single stage to consider multi-stages of a product and its supply chain. The method is exemplified by a case study from the petrochemical industry, namely the early stages of the value chain towards the production of carbon fiber composite materials. Main findings from the application of the method are presented and illustrated with detail analyses for selected countries in the third section. The fourth section is dedicated to discussing the significance of considering resource supply chain to better describe the geopolitical risk implications. The article finishes with a conclusion.

\section{Method}

LCA has been used to evaluate the potential impacts of goods and services on the three areas of protections (AoPs): human health, ecosystem service and natural resources. These are the safeguard subjects that need to be protected for future generations. While established LCA methods and databases exist to address impacts on human health and ecosystem service, the consideration of the AoP natural resources is controversial within the current LCA literature (Drielsma et al., 2016). Dewulf et al. (2015) recently provided a new framework that elaborates on the definition of the AoP natural resources to evaluate direct impacts from their use either within the classical LCA or other methods that attempt to assess the socio-economic implications of resource consumption within the LCSA framework. The framework provides five perspectives that define safeguard subjects for the AoP natural resources in the life cycle impact assessment (LCIA). These are: asset, provisioning capacity, global functions, supply chain and human welfare. In this context, the main goal of this paper is to elaborate the methodological aspects of integrating the concept of criticality into LCA to 
address the impacts from the use of resources meaningfully. This broadens the scope of current LCA practice from being used as only an environmental impact assessment tool to include other aspects such as geopolitical and social components in addition to the geological aspects to extend it to LCSA context. By identifying the full upstream supply chain of a producing company the geopolitical supply risks are analyzed. For this, the geopolitical supply risk assessment method recently proposed by Gemechu et al. (2015a) is further extended. The methodological ground is illustrated in this section. The Geopolitical Supply Risk (GPSR) indicator of Gemechu et al. (2015a) considers a single-stage supply chain for commodities traded from raw material sourcing countries to product-producing countries, illustrated by critical raw materials. The concentration was calculated as the HerfindahlHirschman-Index (HHI) of the producing countries (Calkins, 1983), whereas the political risk was measured as the Worldwide Governance Indicators in its dimension "political stability and absence of violence/terrorism" (WGI-PV) (Kaufmann et al., 2010), weighted by the share of the import flow from all imports of the country, expressed in equation 1. In comparison to the previously reported, the method for the calculation of the risk factor has been extended in two aspects: a) the GPSR indicator now includes the consideration of domestic production in the calculation and b) the multi-stage character of serial supply chains is accommodated in the method.

$G P S R=H H I_{\text {production }} * \overline{W G I_{\text {lmport }}}$

Domestic production as a sourcing option which is "risk-free" from a geopolitical perspective, thus the political stability of a trading partner country is weighted by the share of the sum of total import flows and domestic production all together. The complete calculation for the Geopolitical Supply Risk in a single-stage supply chain is expressed in equation 2.

$$
G P S R_{A C}=H H I_{A} * \overline{W G I_{A C}}=\sum_{i} \frac{p_{A i}^{2}}{P_{A}^{2}} * \sum_{i} g_{i} \frac{f_{A i c}}{p_{A c}+F_{A c}}
$$

Hereby, $G_{P S R_{A C}}$ is the Geopolitical Supply Risk factor for utilizing a commodity $A$ (which is produced in countries $i$ ) in country $c ; p_{A i}$ is the production of the commodity $A$ in country $i ; P_{A}=\sum_{i} p_{A i}$ is the global commodity production. $g_{i}$ is the political stability score of country $i$, rescaled from its WGI-PV score; $f_{A i c}$ is the import tonnage from country $i$ to country $c ; F_{A C}=\sum_{i} f_{A i c}$ is the sum of all import tonnage to country $c$. Both the concentration factor $H H I$ as well as the governance factor $\overline{W G I_{c}}$ take values between 0 and 1 , therefore the Geopolitical Supply Risk factor will also take values between 0 and 1.

For the calculation of the Geopolitical Supply Risk in supply chains with two or more stages, the execution gets more complicated, as it has (at least) two commodities being traded, referred to here as commodities A and B. Figure 1 illustrates these possible country-commodity-relations with a fictional example. The above mentioned parameters are additionally indexed with these commodities. Intermediate countries may now act as a link between countries which do not have direct trade connections (neither for commodity A nor for B). These intermediate countries are assumed to carry forward the upstream geopolitical supply risk emerging from sourcing countries to downstream countries. 


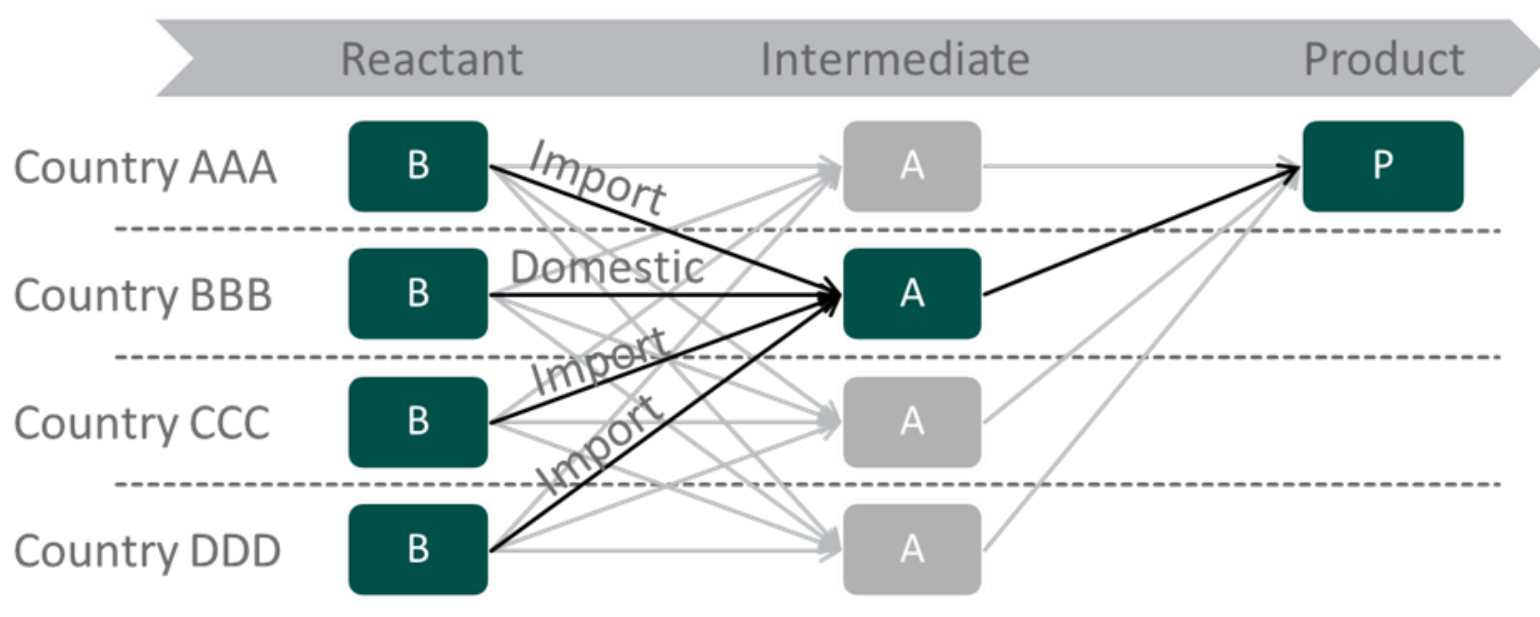

Figure 1: Example for trade flows between reactant producing countries and intermediate trade partner countries for a hypothetical two-stage supply chain.

The total $G P S R_{c}$ in the two-stage supply chain is calculated from the concentration of the production of reactant commodity $B$ and the political stability of the import countries, weighted by both the share of imports from these reactant producing countries to any intermediate producing country of a country $c$ and the input-share (import and domestic production) of these intermediate producing countries concerning intermediate commodity $A$.

$G P S R_{B A c}=H H I_{B} * \overline{W G I_{B A c}}=\sum_{i} \frac{p_{B i}^{2}}{P_{B}^{2}} * \sum_{i} \sum_{k} g_{i} \frac{f_{B i k}}{p_{B k}+F_{B k}} \frac{f_{A k c}+\delta_{k c} p_{A c}}{p_{A c}+F_{A c}}$

$G P S R_{B A C}$ is the Geopolitical Supply Risk factor concerning the reactant commodity $B$ (upstream in the supply chain) transformed to commodity $A$ in a country c. Here, $p$ is the single-country production; $i$ is any country and $k$ is any intermediate country; $P$ is the global production; $g_{i}$ is the political stability score of country $i$, rescaled from its WGI-PV score; $f$ is the country-to-country import tonnage $\left(f_{B i k}\right.$ : reactant commodity $B$ from country $i$ to country $k ; f_{A k c}$ : intermediate commodity $A$ from country $k$ to country $c), F$ is the sum of all import tonnage to a country $\left(F_{B k}\right.$ :imports of commodity $B$ to country $k, F_{A c}$ : imports of commodity $A$ to country $c . \delta_{k c}$ is 1 if $k$ is equal to $c$ and 0 in all other cases. As all factors again take values between 0 and 1 , the GPSR also takes values between 0 and 1 . See the Supplementary Material for the calculation formula for the three-stage supply chain.

Carbon fibers are long and thin strand high-performance materials composed mostly of carbon atoms (more than $90 \%$ of weight composition). The atoms are bound together by controlled pyrolysis to form parallel aligned fibers with excellent tensile strength, low densities, and high thermal and chemical stabilities, good thermal and electrical conductivities, and excellent creep resistance (Huang, 2009; Park and Heo, 2015). The extraordinary properties of carbon fibers, which depend on precise production processes, present a wide range of high-technology applications such as aerospace and military equipment, building and construction materials, electronic devices, and sporting goods. There are several precursors to produce carbon fiber, but the most widely used are cellulosic PAN and pitch based precursors (Huang, 2009).

The main supply chain of PAN-based carbon fiber is shown in Figure 2. It usually starts from the extraction of crude petroleum, which undergoes refining processes to obtain propene. Propene can be produced by breaking the long-chain organic molecules of hydrocarbons in crude oil either through steam or catalytic cracking processes. The former is the most widely used technique. Propene can also be made from natural gas feedstock, but here the focus is on the petroleum path. Acrylonitrile is mainly produced from the ammoxidation of propene, also called the Sohio-process 
(from the company Standard Oil of Ohio) (Cespi et al., 2014). The process involves the production of nitriles by using ammonia and oxygen and alkenes as substrates. Acrylonitrile undergoes a radical polymerization process to get PAN (Huang, 2009). The further treatment of PAN precursor to get the carbon fiber highly depends on the desired properties and is usually executed at a single carbon fiber production facility and thus these subsequent materials are typically not traded in commerce. Global production capacity is rising quickly to match the increasing technology demand for carbon fiber composites.

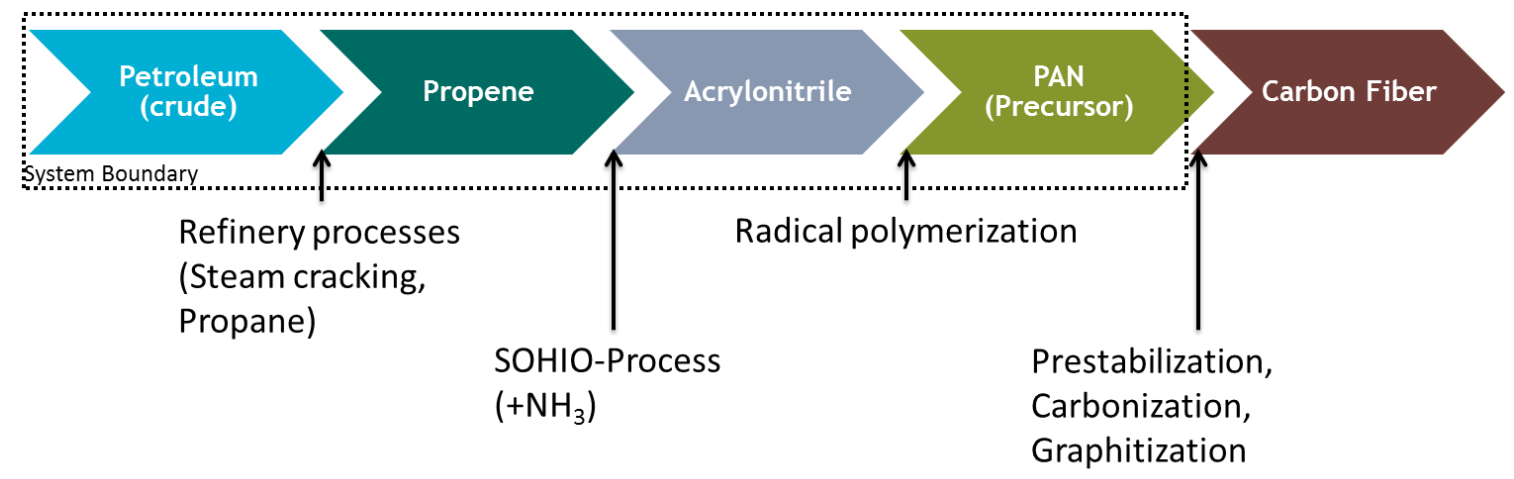

Figure 2: System boundary for carbon fiber production

Three different data types are required for the calculation of the Geopolitical Supply Risk: national domestic production volumes for all supply stages, international import-export trade volumes in all supply stages, and a measure of the political stability of countries. National production volume sources differ between petroleum, propene and acrylonitrile. The BP statistical yearbook is used for petroleum production covering 49 producing countries and $99 \%$ of worldwide production (BP, 2014). Data for the chemical industry is likely to be proprietary. For propene and acrylonitrile, production capacities are used instead of annual production volumes: full capacity utilization for the risk calculation is assumed (if instead capacity was not fully utilized, supply risk could be mitigated by higher capacity utilization). For propene, the production capacities of 20 countries covering $71 \%$ of global capacity were identified through sources from companies (INEOS, 2015), industry experts (CIEC Promoting Science, 2015; plastemart, 2014; Smith et al., 2012) and government institutions (U.S. Energy Information Administration, 2015). For acrylonitrile, a PCl report listed the capacities of sites in 14 countries, covering $94 \%$ of the global capacities ( $\mathrm{PCl}, 2013)$.

The import-export data were extracted from the United Nations Commodity Trade (UN Comtrade) database (UN, 2015). The Harmonized System (HS) reporting for year 2013 contains the commodities petroleum (HS 270900 "Petroleum oils, oils from bituminous minerals, crude"), propene (HS 290122 "Propene (propylene)") and acrylonitrile (HS 292610 "Acrylonitrile"). The total disclosed import volumes of petroleum accounted for $49 \%$ of global production. Propene was used domestically very often and only $7 \%$ was estimated to be traded internationally. Total imports of propene accounted for $24 \%$ of acrylonitrile production capacity. 
Table 1: Supply chain data concerning crude petroleum, propene and acrylonitrile.

\begin{tabular}{llll} 
Data & Petroleum & Propene & Acrylonitrile \\
\hline Total production volume & $4130 \mathrm{Mt}$ & $100.4 \mathrm{Mt}$ & $5900 \mathrm{kt}$ \\
\hline Disclosed production & $4071 \mathrm{Mt}$ & $71.4 \mathrm{Mt}$ & $5565 \mathrm{kt}$ \\
\hline Number of disclosed countries & 49 & 20 & 14 \\
\hline Production concentration (HHI) & 0.0630 & 0.0999 & 0.1321 \\
\hline UN Comtrade HS code & 270900 & 290122 & 292610 \\
\hline Total import volume & $2036 \mathrm{Mt}$ & $6800 \mathrm{kt}$ & $1428 \mathrm{kt}$
\end{tabular}

For the evaluation of the political stability of the countries, the Worldwide Governance Indicators (WGI) published by the World Bank were used in their meta-indicator Political Stability and Absence of Violence/Terrorism (WGI-PV), again with data for year 2013, and using the score rather than the rank of each country (Kaufmann and Kraay, 2015). Scores of Worldwide Governance Indicators are displayed in values from around -2.5 (very unstable) to 2.5 (very stable). Original values are normalized to a mean of 0 and a standard deviation of 1 . For the calculation these values are linearly rescaled so that a factor of 0 is very stable and 1 is very unstable.

Overall, production and trade data were collected for at least one of the three supply chain stages for 145 countries. Here it is worth mentioning that all 145 countries are not necessarily producing carbon fiber, but at least they are involved in the supply chain of raw material that could be used in the manufacturing process. Of these countries, 135 had domestic production or imports for petroleum, 90 for propene and 72 for acrylonitrile. This way, a three-stage supply chain from petroleum to acrylonitrile was identified and evaluated for 72 countries worldwide. 54 countries had domestic production or imports for all three commodities. The data contains 1244 country-tocountry connections (import or domestic production) for petroleum, 396 for propene and 322 for acrylonitrile. Table 2 shows a summary for the trade data along the different supply stages. Six values for the geopolitical supply risk can be calculated for each country perspective within the system boundary: one for each material (risk of acrylonitrile imports, risk of propene imports, risk of petroleum imports), and three for risks throughout the supply chain (risk of propene imports in acrylonitrile partner countries, risk of petroleum imports in propene partner countries and risk of petroleum imports in propene partner countries of acrylonitrile partner countries). The number of considered supply chain paths for the multi-stage supply chains rises to over 60 thousand connections for the full consideration of petroleum to propene to acrylonitrile.

Table 2: Information on trade data gathered from the World Bank and UN Comtrade

\begin{tabular}{llllll} 
Data & Petroleum & $\begin{array}{l}\text { Petroleum- } \\
\text { Propene }\end{array}$ & Propene & $\begin{array}{l}\text { Petroleum-Propene- } \\
\text { Acrylonitrile }\end{array}$ & $\begin{array}{l}\text { Propene- } \\
\text { Acrylonitrile }\end{array}$ \\
\hline $\begin{array}{l}\text { Number of countries } \\
\text { (total 145) }\end{array}$ & 135 & 90 & 90 & 72 & 72 \\
\hline $\begin{array}{l}\text { Number of identified } \\
\text { connections }\end{array}$ & 1244 & 9398 & 396 & 61671 & 322 \\
\hline $\begin{array}{l}\text { Average WGI-PV } \\
\text { (original score) }\end{array}$ & 0.68 & 0.64 & 0.85 & 0.29 & 2378 \\
\hline $\begin{array}{l}\text { Average WGI-PV } \\
\text { (rescaled 1 to 0) }\end{array}$ & 0.36 & 0.37 & 0.33 & 0.44 & 0.74 \\
\hline
\end{tabular}




\section{Results}

The production concentration was calculated to be lowest for crude petroleum (HHI 0.063), middle for propene refinery capacity ( $\mathrm{HHI} 0.0999)$ and highest for acrylonitrile ( $\mathrm{HHI} 0.1321)$. However, all these concentrations are below most metal market concentrations and also below the threshold typically evaluated as critical (DOJ and FTC, 2010). The largest oil producing countries in 2013 were Saudi Arabia (13.1\% of global production), Russia (12.9\%) and the United States (10.8\%) (BP, 2014). More than 50 countries have significant, disclosed petroleum production volumes, leading to the low production concentration. Propene production capacities are largest in China, the United States, South Korea and Japan(CIEC Promoting Science, 2015; plastemart, 2014; U.S. Energy Information Administration, 2015), all being typical locations for large-scale refineries and the production of base chemicals. The largest acrylonitrile production capacities are located in the United States, South Korea and Japan. There are also significant production capacities for both propene and acrylonitrile in Europe, but distributed among the individual countries, particularly in Germany, the United Kingdom and the Netherlands ( $\mathrm{PCl}, 2013)$.

In total, 145 countries got at least one of the risk values, with 54 countries getting geopolitical supply risk factors for all six perspectives, as shown in Figure 3 (see Supporting Information for table with all 145 countries). The highest single risk factor was calculated for Nigeria with $135 \%$, as this country has no domestic production of acrylonitrile and imports all of its acrylonitrile from Pakistan, a country evaluated as particularly unstable in the WGI-PV. The lowest risk values with a value of $0 \%$ appeared for countries with domestic production only (and no disclosed imports), such as Iraq (petroleum), Iran (petroleum and propene) and Turkey (acrylonitrile). 


\begin{tabular}{|c|c|c|c|c|c|c|c|}
\hline Commodity C & & & & Petroleum & & & $C$ \\
\hline Commodity $B$ & & Petroleum & & Propene & Propene & & $B$ \\
\hline Commodity C & Petroleum & Propene & Propene & Acrylonitrile & Acrylonitrile & Acrylonitrile & $A$ \\
\hline Argentinia & $0 \%$ & $15 \%$ & $38 \%$ & $15 \%$ & $39 \%$ & $73 \%$ & ARG \\
\hline Australia & $18 \%$ & $18 \%$ & $0 \%$ & $32 \%$ & $50 \%$ & $66 \%$ & AUS \\
\hline Austria & $44 \%$ & $36 \%$ & $32 \%$ & $35 \%$ & $9 \%$ & $40 \%$ & AUT \\
\hline Belarus & $41 \%$ & $3 \%$ & $62 \%$ & $3 \%$ & $62 \%$ & $0 \%$ & BLR \\
\hline Belgium & $21 \%$ & $31 \%$ & $33 \%$ & $33 \%$ & $14 \%$ & $45 \%$ & BEL \\
\hline Brazil & $7 \%$ & $15 \%$ & $39 \%$ & $15 \%$ & $36 \%$ & $3 \%$ & BRA \\
\hline Bulgaria & $41 \%$ & $37 \%$ & $39 \%$ & $30 \%$ & $43 \%$ & $66 \%$ & BGR \\
\hline Canada & $5 \%$ & $15 \%$ & $38 \%$ & $15 \%$ & $1 \%$ & $50 \%$ & CAN \\
\hline Chile & $33 \%$ & $15 \%$ & $38 \%$ & $31 \%$ & $50 \%$ & $66 \%$ & $\mathrm{CHL}$ \\
\hline China & $22 \%$ & $24 \%$ & $6 \%$ & $27 \%$ & $11 \%$ & $41 \%$ & CHN \\
\hline Columbia & $0 \%$ & $9 \%$ & $52 \%$ & $33 \%$ & $26 \%$ & $45 \%$ & COL \\
\hline Croatia & $37 \%$ & $36 \%$ & $31 \%$ & $37 \%$ & $32 \%$ & $45 \%$ & HRV \\
\hline Czech Rep. & $40 \%$ & $36 \%$ & $32 \%$ & $35 \%$ & $5 \%$ & $42 \%$ & CZE \\
\hline Denmark & $9 \%$ & $36 \%$ & $31 \%$ & $36 \%$ & $38 \%$ & $53 \%$ & DNK \\
\hline Iminican Rep. & $42 \%$ & $15 \%$ & $38 \%$ & $24 \%$ & $8 \%$ & $44 \%$ & DOM \\
\hline Ecuador & $0 \%$ & $19 \%$ & $51 \%$ & $14 \%$ & $34 \%$ & $92 \%$ & ECU \\
\hline Egypt & $2 \%$ & $35 \%$ & $42 \%$ & $30 \%$ & $12 \%$ & $58 \%$ & EGY \\
\hline Ethiopia & $32 \%$ & $31 \%$ & $50 \%$ & $36 \%$ & $42 \%$ & $55 \%$ & ETH \\
\hline Finland & $39 \%$ & $27 \%$ & $30 \%$ & $34 \%$ & $20 \%$ & $40 \%$ & FIN \\
\hline France & $39 \%$ & $36 \%$ & $42 \%$ & $32 \%$ & $12 \%$ & $40 \%$ & FRA \\
\hline Germany & $36 \%$ & $35 \%$ & $5 \%$ & $34 \%$ & $6 \%$ & $8 \%$ & DEU \\
\hline Greece & $46 \%$ & $38 \%$ & $46 \%$ & $40 \%$ & $47 \%$ & $52 \%$ & GRC \\
\hline Hungary & $42 \%$ & $37 \%$ & $32 \%$ & $19 \%$ & $8 \%$ & $57 \%$ & HUN \\
\hline India & $33 \%$ & $33 \%$ & $0 \%$ & $19 \%$ & $21 \%$ & $58 \%$ & IND \\
\hline Indonesia & $11 \%$ & $10 \%$ & $10 \%$ & $26 \%$ & $1 \%$ & $83 \%$ & IDN \\
\hline Ireland & $29 \%$ & $17 \%$ & $40 \%$ & $37 \%$ & $40 \%$ & $53 \%$ & IRL \\
\hline Israel & $31 \%$ & $20 \%$ & $33 \%$ & $31 \%$ & $15 \%$ & $38 \%$ & ISR \\
\hline Japan & $31 \%$ & $31 \%$ & $0 \%$ & $31 \%$ & $0 \%$ & $1 \%$ & JPN \\
\hline Korea, Rep. & $34 \%$ & $34 \%$ & $2 \%$ & $32 \%$ & $2 \%$ & $5 \%$ & KOR \\
\hline Latvia & $19 \%$ & $15 \%$ & $38 \%$ & $36 \%$ & $25 \%$ & $41 \%$ & LVA \\
\hline Luxembourg & $21 \%$ & $21 \%$ & $32 \%$ & $31 \%$ & $35 \%$ & $44 \%$ & LUX \\
\hline Malaysia & $8 \%$ & $8 \%$ & $1 \%$ & $26 \%$ & $5 \%$ & $60 \%$ & MYS \\
\hline Mexico & $0 \%$ & $12 \%$ & $55 \%$ & $14 \%$ & $28 \%$ & $25 \%$ & MEX \\
\hline Netherlands & $35 \%$ & $33 \%$ & $15 \%$ & $33 \%$ & $15 \%$ & $5 \%$ & NLD \\
\hline Peru & $20 \%$ & $15 \%$ & $38 \%$ & $15 \%$ & $5 \%$ & $53 \%$ & PER \\
\hline Philippines & $32 \%$ & $31 \%$ & $2 \%$ & $15 \%$ & $1 \%$ & $50 \%$ & PHL \\
\hline Poland & $40 \%$ & $30 \%$ & $37 \%$ & $33 \%$ & $15 \%$ & $37 \%$ & POL \\
\hline Portugal & $39 \%$ & $43 \%$ & $50 \%$ & $13 \%$ & $12 \%$ & $73 \%$ & PRT \\
\hline Romania & $22 \%$ & $33 \%$ & $54 \%$ & $35 \%$ & $5 \%$ & $42 \%$ & ROU \\
\hline Russia & $0 \%$ & $0 \%$ & $0 \%$ & $0 \%$ & $1 \%$ & $0 \%$ & RUS \\
\hline Singapore & $28 \%$ & $28 \%$ & $1 \%$ & $30 \%$ & $39 \%$ & $70 \%$ & SGP \\
\hline Slovakia & $41 \%$ & $42 \%$ & $34 \%$ & $36 \%$ & $32 \%$ & $38 \%$ & SVK \\
\hline Slovenia & $14 \%$ & $41 \%$ & $26 \%$ & $36 \%$ & $32 \%$ & $42 \%$ & SVN \\
\hline South Africa & $41 \%$ & $22 \%$ & $60 \%$ & $32 \%$ & $27 \%$ & $40 \%$ & ZAF \\
\hline Spain & $43 \%$ & $30 \%$ & $43 \%$ & $27 \%$ & $34 \%$ & $60 \%$ & ESP \\
\hline Sweden & $34 \%$ & $35 \%$ & $31 \%$ & $33 \%$ & $18 \%$ & $37 \%$ & SWE \\
\hline Switzerland & $48 \%$ & $36 \%$ & $38 \%$ & $33 \%$ & $16 \%$ & $37 \%$ & CHE \\
\hline Thailand & $21 \%$ & $21 \%$ & $0 \%$ & $23 \%$ & $3 \%$ & $15 \%$ & THA \\
\hline Tunesia & $11 \%$ & $33 \%$ & $43 \%$ & $32 \%$ & $50 \%$ & $79 \%$ & TUN \\
\hline Ukraine & $39 \%$ & $0 \%$ & $65 \%$ & $0 \%$ & $0 \%$ & $86 \%$ & UKR \\
\hline ited Kingdom & $17 \%$ & $37 \%$ & $40 \%$ & $35 \%$ & $38 \%$ & $3 \%$ & GBR \\
\hline United States & $15 \%$ & $15 \%$ & $1 \%$ & $15 \%$ & $1 \%$ & $0 \%$ & USA \\
\hline Venezuela & $0 \%$ & $16 \%$ & $38 \%$ & $33 \%$ & $15 \%$ & $37 \%$ & VEN \\
\hline Vietnam & $2 \%$ & $2 \%$ & $0 \%$ & $32 \%$ & $36 \%$ & $64 \%$ & VNM \\
\hline Supply Chain & Petroleum & Petrol.-C3H6 & C3H6 & Petr.-Pro.-AN & C3H6-AN & AN & \\
\hline
\end{tabular}

Figure 3: Global results of the calculation for the Geopolitical Supply Risk factor 


\subsection{Case study: Russia, Peru, Japan and Greece}

Comparing the risk scores, which represent the risk in a country to access chemical supply, four categories of countries emerge: (a) low-risk countries, (b) resource-rich countries, (c) chemical industry countries, (d) high-risk countries. Russia, Peru, Japan and Greece exemplify these four patterns resulting from Geopolitical Supply Risk factors in different supply chain stages. Russia is an example of a low-risk country, showing high domestic production and low imports throughout all three supply chain steps, and consistently low risk values. Peru is an example of a country with significant domestic petroleum production, but without a strong chemical industry, therefore still reliant on imports from countries in the acrylonitrile supply chain. Japan is an example of a country with a well-developed chemical industry and refinery capacities, but without an adequate domestic oil production. Therefore, Japan is showing very low risk when looking only at the chemical industry, but higher risk in the early supply chain. Greece is a typical high-risk country (as apparent among smaller countries, particularly in Europe), without a strong chemical industry, and is therefore reliant on the refining capacities of other countries that are also often petroleum importers: all six risk factors for Greece are above $30 \%$. Figure 4 illustrates the simplified supply chains for the acrylonitrile sourcing of these four countries.

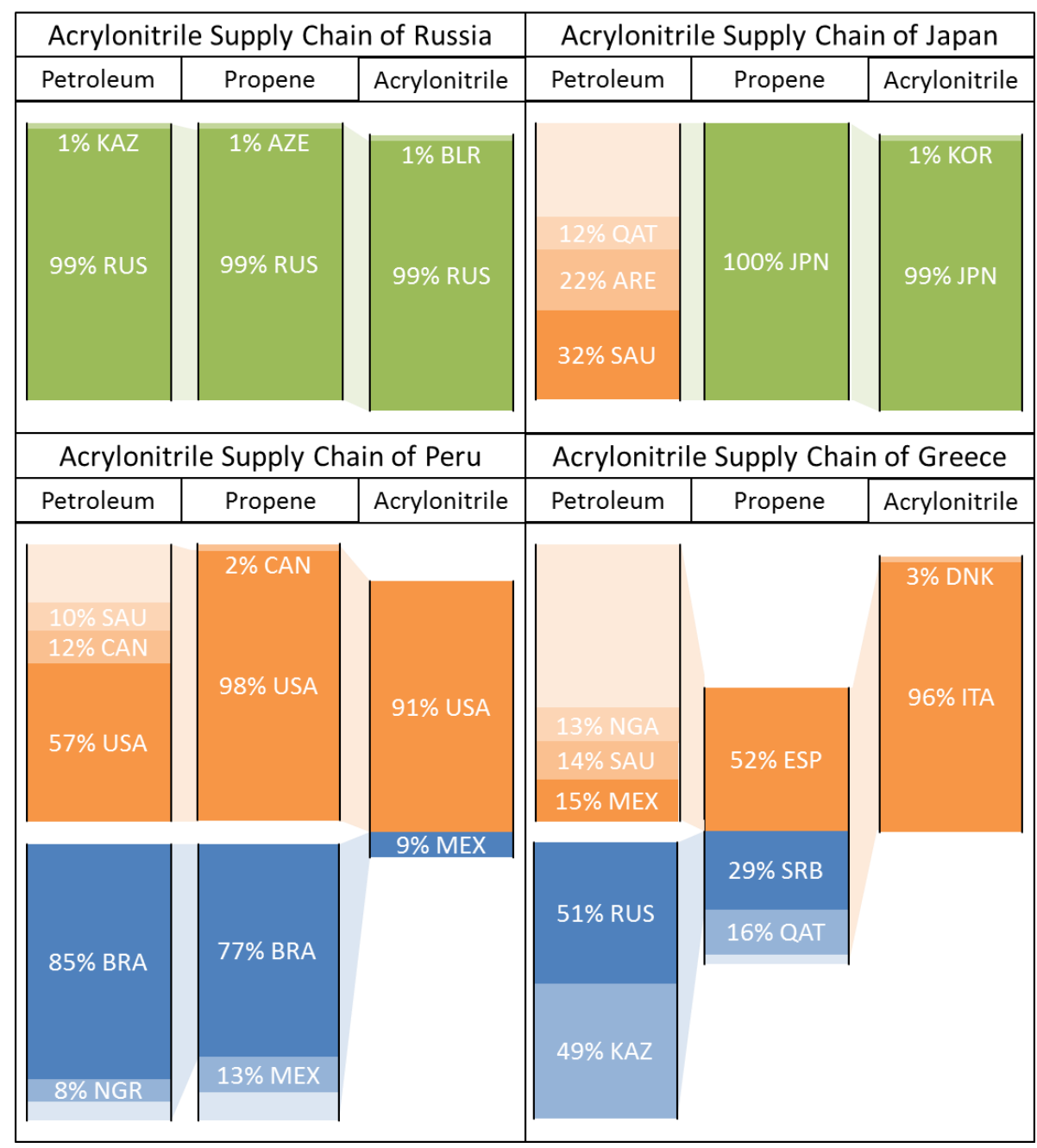

Figure 4: Acrylonitrile supply chain for Russia, Peru, Japan and Greece (simplified). Displayed is the contribution to inputs of the commodity, through domestic production or imports. 
Russia has very strong domestic fossil fuel production, propene refining capacity and domestic acrylonitrile production. Therefore, domestic production is the dominant source for all three supply chain stages of the Russian acrylonitrile supply chain. The Geopolitical Supply Risk factors are minimal in all scopes (no value above $1 \% 0$ ) and geopolitical supply risks cannot be practically lowered any further. Therefore, a further reduction of geopolitical supply risks is difficult for countries that already have a low-risk profile in the assessment.

The highest risk score for Peru's Carbon Fiber supply chain is calculated for the direct sourcing of acrylonitrile with a GPSR of $53 \%$, while the lowest risk factor is calculated for the propene sourcing in its acrylonitrile chain with a GPSR of $5.4 \%$. Peru does have significant domestic production of crude oil, but not for propene or acrylonitrile. Therefore, the acrylonitrile imported to Peru comes from the United States and Mexico. The United States, however, is a major domestic producer of propene, with minimal imports from Canada. Mexico sources its propene mainly from Brazil and partly from Asia. The absence of domestic acrylonitrile production implies a geopolitical supply risk for Peru's acrylonitrile imports, but its acrylonitrile partner countries can rely on domestic propene production and therefore do not pose a significant Geopolitical Supply Risk in the two-stage scope "C3H6-AN". The petroleum potentially used in Peru's acrylonitrile supply chain is mainly sourced from the United States, Canada, Saudi Arabia (all three petroleum sourcing for U.S.), Brazil and Nigeria (petroleum sourcing for Brazil), resulting in a GPSR of $15 \%$ for the three-stage scope "Petroleum-C3H6-AN". If Peru's acrylonitrile-utilizing industry were to change its current sourcing patterns, one possible path would be increased domestic production of both propene and acrylonitrile. Implementing only a propene producing industry would not reduce the dependency of acrylonitrile imports from the United States and Mexico; whereas implementing only an acrylonitrile producing industry would imply a dependency on its propene supply chain, which is currently completely dominated by imports from the United States (GPSR 37\%o). Therefore, both a propene and an acrylonitrile producing industry would be required. The direct petroleum supply chain of Peru, however, shows strong domestic production (51\%) with some imports from Ecuador and Nigeria, among other countries, and a lower GPSR of 20\%o. See Supporting Information for a Figure including the petroleum and the propene supply chain of Peru.

Japan shows the opposite pattern for its acrylonitrile supply: for both propene and acrylonitrile, the domestic production capacity is much larger than import volumes, and therefore the GPSR is below 1 $\%$ for all supply chain scopes without crude oil. However, crude oil is mainly imported to Japan with Saudi Arabia, the United Arab Emirates and Qatar being the main trading partners. None of these countries are evaluated as particularly stable, leaving Japan with a GPSR for the three-stage supply chain of $31 \%$. Japanese petrochemical industries can reduce their Geopolitical Supply Risk factors by changing their supply routes of crude oil to other, more political stable countries. Significant domestic production of crude oil is not available for Japan.

The case of the high-risk profile country Greece is more complicated and strategies for a reduction of the Geopolitical Supply Risk factors are difficult to formulate. Greece is importing most of its acrylonitrile from Italy, whereas Italy imports its propene mainly from Spain and Serbia. Spain and Serbia themselves, however, do not have significant production of crude oil and are therefore importing crude oil. Spain has many different trade partners for crude oil imports; Mexico, Saudi Arabia and Nigeria are the most important among these, but do not make up more than half of Spanish imports for crude oil. Serbia is importing its crude oil from Russia and Kazakhstan. 


\section{Discussion}

For the past two decades, a number of LCIA methods have been developed in an attempt to address the direct impact from the use of natural resources, yet there is not globally agreed upon method. There are ongoing debates within the LCA community that the AoP natural resources needs to be redefined and the LCIA approaches for resources need to be broadened from their environmental focus to include social and economic aspects, including to meaningfully address both the short- and long-term perspective of resource scarcity under the LCSA framework. One recent attempt to provide a framework of conceptualizing the resource impact assessment is through integrating traditional LCA with the concept of resource criticality (Sonnemann et al. 2015). Dewulf et al. (2015) redefine the AoP natural resources and propose alternative frameworks to address the life cycle impact of natural resources for five different perspectives. Their approach considers natural resources as the building blocks of goods and services essential for human welfare. In this case, the impact mechanism starts at the elementary flows which are normally considered in the traditional LCA but it goes beyond the environmental impacts through including the socio-economic mechanism along the supply chain, these are, for example, the supply risks due to geopolitical circumstance or social risks due to local conflicts. The main focus of the present paper is to assess the geopolitical aspect as a potential disrupting factor for the sustainable supply of a resource in a short-term time perspective. When linked with the functional unit of a specific product's life cycle, then the geopolitical supply risk assesses the socio-economic condition that impacting the product system. However, some argue that socio-economic aspects should be addressed separately using different tools than LCA, for example, that LCA is designed to assess the "snapshot" potential impacts of a product system on the environment per the functional unit. Therefore, it is difficult to address the socio-economic impact of a product which often arise due to a sudden shifts in demand or political situation using the current LCA (Drielsma et al., 2016). One solution suggested by Sonnemann et al., (2015) and acknowledged by Drielsmaa et al., (2016). is the integration of LCA and the socioeconomic dimension of natural resource impacts under the LCSA framework.

This paper builds on the conceptual framework for geopolitical related supply risk proposed by Sonnemann et al., (2015) and develops beyond the subsequent methodological advancement provided by Gemechu et al., (2015). The application of the Geopolitical Supply Risk factor to the petrochemical supply chain of carbon fibers has illustrates the implementation of this methodological extension. In comparison to the previously proposed calculation for the supply risk factor, both domestic production (which is assumed to pose no geopolitical supply risk) and multistage supply chains are now included. By including domestic production, an important component of resource supply is considered in the value chain. For countries like Russia (which has a high WGI risk factor), domestic production provides the most significant means by which resource risk is mitigated. If domestic supply were not considered the results for Russia would appear entirely different. Conversely, countries like Peru do not have a physical scarcity of petroleum, but they are completely dependent on imports for acrylonitrile as they lack domestic chemical industries. The resource strategies for such countries to reduce their resource supply risk could include to promote (foreign) investment in chemical industries, to encourage research and development in chemical processes, or to develop partnerships with chemical industry intensive countries like Japan for education and information diffusion. The policy options for countries are similar to the national strategies for rare earths as critical raw materials identified by Barteková and Kemp (2016). For countries and companies alike a quantitative indicator-based assessment enables measuring progress towards sustainable supply chains. By considering multiple stages in commodity resource production a more 
realistic representation of real-world supply chains has been modelled. In the case of PAN, three stages are considered. For other extractive resources different value chains would need to be considered. In the case of metals and minerals, the most important stages in the supply chain that need to be included are mining, smelting refining, fabrication and manufacturing. Metals and minerals supply chains are complex as they involve interrelated activities (processes) and considerable international trading functions. Therefore, it requires a better mapping and resolution to track or trace the flow along multiple stages (Young et al., 2013).

Identification of Geopolitical Supply Risk factors corresponding to the different scopes of the supply chain points to policy options to reduce the supply risk based on international trade patterns. The geopolitical risk due to supply concentration or political instability of the resource intensive countries can result in volatility in resource markets as a short-term impact. Hence, it is relevant to the strategic decision-making for companies. The proposed extended method can identify specific trade risks, which consider the particular trade patterns with real import shares and calculate countryspecific risk factors. It could be applied by companies to identify the potential sources for the risk and make an informed-decision in the strategy, environmental management or supply chain management department. The application requires an understanding of the upstream supply chain, its global commodity markets, the data sources and life cycle impact assessment. One of the strategies to reduce the geopolitical related risk is to use alternative sources of supply. In this regard, the method allows to map the risk contribution of all involved trade partners and based on that it is possible to suggest an alternative supplier that would minimize the risks. The Geopolitical Supply Risk factors can be reduced by increasing domestic production in all supply chain stages or by selection of more stable trading partner countries.

One of the main limitations of this method is the link to the life cycle assessment which is not yet clearly developed. Environmental impacts in LCA are calculated per functional unit set in the goal and scope definition. However, the Geopolitical Supply Risk Factors only provide relative risks between the resources and are not yet linked to the functional unit. Further development is needed to define the risk so that they provide a value of each resource computed with the functional unit. Moreover, there is no proposed endpoint characterization factor (damage oriented factor) which links the Geopolitical Supply Risk emerging from trade (impact) to possible damages (e.g., extra costs for insurance, risk mitigation or from supply shortages).

The method is limited by availability and quality of data, particularly the quality of trade data and production volumes. The trade data is dependent on (partially voluntary) disclosure of trade tonnage in the UN Comtrade database. Import- and export volumes sometimes display discrepancies, indicating possible data improvements. Using more specific HS codes (UN Comtrade currently only discloses up to 6-digit codes, but 8-digit codes could also be assessed) can also help identifying the relevant trade patterns for commodities. For highly specialized commodities which cannot be harmonized there is a supplier risk independent from geopolitical considerations, assessed for example based on supplier reliability and the availability of second source suppliers. Note also that results are for the year 2013, and are subject to changes as commodity markets, international trade patterns and political circumstances will shift over time. Thus, the results of the case study countries represent a snapshot in time. This asks the user to regularly (e.g. annually or after major changes in the supply chain) reevaluate the Geopolitical Supply Risk, which might also enable an iterative improvement of the underlying data. 


\section{Conclusion}

In this article, an extension of the previously proposed Geopolitical Supply Risk methodology for evaluating international production and trade patterns for commodities is developed. The extension accounts for domestic production and multi-stage supply chains. The calculation now uses production data on country-level together with international import-export data and the Worldwide Governance Indicator Political Stability and Absence of Violence/Terrorism to evaluate the geopolitical supply risks of a specific upstream supply chain of a country. This methodology is applied to the early petrochemical supply chain of polyacrylonitrile-based carbon fibers: Crude petroleum is refined to propene, which can be transformed to acrylonitrile using ammonia in the SOHIO process; all three commodities are identified by 6-digit Harmonized System (HS) commodity codes in the UN Comtrade database. The distinction of these trade patterns without the availability of distinct HS commodity codes is a possible matter of future research. The GPSR factors for 54 countries in six supply chain scopes are calculated, which shows at least four different supply risk patterns. The specific acrylonitrile supply chain of Peru shows a strong dependence on the United States and Brazil concerning imports of acrylonitrile and sourcing of propene and crude petroleum.

The geopolitical supply risk factor can be used as a socio-economic indicator under the life cycle sustainability assessment (LCSA), a framework that attempts to evaluate the performance of a product or service from the environmental, economic and social aspects of sustainability per functional unit. The geopolitical supply risk factor provides additional information to the classical environmental assessment to support the decision making process for companies in their pursuit to secure a sustainable supply of resources that meet the technological requirement. Despite the fact that it is a new attempt to include geopolitical aspects in LCSA, the link to the functional unit still needs to be developed. The future perspective will be to develop a well-established endpoint indicator that links the consequence of any potential supply disruption due to geopolitical factor on human welfare. Developing a socio-economic cause and effect mechanism that links geopolitical related supply risk to the effect on human welfare benefits is a way forward.

\section{Acknowledgements}

This research was supported by the Bavarian graduate school "Resource strategy concepts for sustainable energy systems" of the Institute of Materials Resource Management (MRM) of the University of Augsburg and the French national research agency (ANR), who is funding the SEARRCH project (ANR-13-ECOT-0005). We thank Nino Haase for useful discussion on the carbon fiber supply chain.

\section{References}

Barteková, E., Kemp, R., 2016. National strategies for securing a stable supply of rare earths in different world regions. Resour. Policy 49, 153-164. doi:10.1016/j.resourpol.2016.05.003

Benoît, C., Norris, G. a., Valdivia, S., Ciroth, A., Moberg, A., Bos, U., Prakash, S., Ugaya, C., Beck, T., 2010. The guidelines for social life cycle assessment of products: just in time! Int. J. Life Cycle Assess. 15, 156-163. doi:10.1007/s11367-009-0147-8

BP, 2014. BP Statistical Review of World Energy 2014.

Bradshaw, A.M., Reuter, B., Hamacher, T., 2013. The Potential Scarcity of Rare Elements for the Energiewende. Green 3, 93-111. doi:10.1515/green-2013-0014 
Calkins, S., 1983. The New Merger Guidelines and the Herfindahl-Hirschman Index. Calif. Law Rev. 71, 402. doi: $10.2307 / 3480160$

Cespi, D., Passarini, F., Neri, E., Vassura, I., Ciacci, L., Cavani, F., 2014. Life Cycle Assessment comparison of two ways for acrylonitrile production: the SOHIO process and an alternative route using propane. J. Clean. Prod. 69, 17-25. doi:10.1016/j.jclepro.2014.01.057

CIEC Promoting Science, 2015. Propene (Propylene) [WWW Document]. URL http://www.essentialchemicalindustry.org/chemicals/propene.html (accessed 6.30.15).

Craig, J.R., Vaughan, D.J., Skinner, B.J., 2011. Resources of the earth: origin, use, and environmental impact, 4th ed. Prentice Hall.

Dewulf, J., Benini, L., Mancini, L., Sala, S., Blengini, G.A., Ardente, F., Recchioni, M., Maes, J., Pant, R., Pennington, D., 2015. Rethinking the Area of Protection "Natural Resources" in Life Cycle Assessment. Environ. Sci. Technol. 49, 5310-5317. doi:10.1021/acs.est.5b00734

DOJ and FTC, 2010. Horizontal Merger Guidelines [WWW Document]. URL http://www.justice.gov/atr/public/guidelines/hmg-2010.pdf

Drielsma, J.A., Russell-Vaccari, A.J., Drnek, T., Brady, T., Weihed, P., Mistry, M., Simbor, L.P., 2016. Mineral resources in life cycle impact assessment-defining the path forward. Int. J. Life Cycle Assess. 21, 85-105. doi:10.1007/s11367-015-0991-7

Duan, H., Wang, J., Liu, L., Huang, Q., Li, J., 2015. Rethinking China's strategic mineral policy on indium: implication for the flat screens and photovoltaic industries. Prog. Photovoltaics Res. Appl. 20, n/a-n/a. doi:10.1002/pip.2654

Gemechu, E.D., Helbig, C., Sonnemann, G., Thorenz, A., Tuma, A., 2015. Import-based Indicator for the Geopolitical Supply Risk of Raw Materials in Life Cycle Sustainability Assessments. J. Ind. Ecol. n/a-n/a. doi:10.1111/jiec.12279

Gemechu, E.D., Sonnemann, G., Young, S.B., 2015. Geopolitical-related supply risk assessment as a complement to environmental impact assessment: the case of electric vehicles. Int. J. Life Cycle Assess. doi:10.1007/s11367-015-0917-4

Graedel, T.E., Barr, R., Chandler, C., Chase, T., Choi, J., Christoffersen, L., Friedlander, E., Henly, C., Jun, C., Nassar, N.T., Schechner, D., Warren, S., Yang, M., Zhu, C., 2012. Methodology of Metal Criticality Determination. Environ. Sci. Technol. 46, 1063-1070. doi:10.1021/es203534z

Graedel, T.E., Reck, B.K., 2015. Six Years of Criticality Assessments: What Have We Learned So Far? J. Ind. Ecol. 00, n/a-n/a. doi:10.1111/jiec.12305

Greenfield, A., Graedel, T.E., 2013. The omnivorous diet of modern technology. Resour. Conserv. Recycl. 74, 1-7. doi:10.1016/j.resconrec.2013.02.010

Habib, K., Hamelin, L., Wenzel, H., 2016. A dynamic perspective of the geopolitical supply risk of metals. J. Clean. Prod. doi:10.1016/j.jclepro.2016.05.118

Huang, X., 2009. Fabrication and Properties of Carbon Fibers. Materials (Basel). 2, 2369-2403. doi:10.3390/ma2042369

INEOS, 2015. Product and Applications [WWW Document]. URL http://www.ineos.com/products/ (accessed 6.30.15).

Johnson, J., Graedel, T.E., 2008. The "hidden" trade of metals in the United States. J. Ind. Ecol. 12, 739-753. doi:10.1111/j.1530-9290.2008.00092.x

Kaufmann, D., Kraay, A., 2015. Worldwide Governance Indicators [WWW Document]. URL http://info.worldbank.org/governance/wgi/index.aspx\#home (accessed 12.1.15).

Kaufmann, D., Kraay, A., Mastruzzi, M., 2010. The Worldwide Governance Indicators: Methodology and Analytical Issues. World Bank Policy Res. Work. Pap. 5430. 
Krohns, S., Lunkenheimer, P., Meissner, S., Reller, A., Gleich, B., Rathgeber, A., Gaugler, T., Buhl, H.U., Sinclair, D.C., Loidl, A., 2011. The route to resource-efficient novel materials. Nat. Mater. 10, 899-901. doi:10.1038/nmat3180

Mancini, L., Benini, L., Sala, S., 2015a. Resource footprint of Europe: Complementarity of material flow analysis and life cycle assessment for policy support. Environ. Sci. Policy 54, 367-376. doi:10.1016/j.envsci.2015.07.025

Mancini, L., Sala, S., Recchioni, M., Benini, L., Goralczyk, M., Pennington, D., 2015b. Potential of life cycle assessment for supporting the management of critical raw materials. Int. J. Life Cycle Assess. 20, 100-116. doi:10.1007/s11367-014-0808-0

Nansai, K., Nakajima, K., Kagawa, S., Kondo, Y., Shigetomi, Y., Suh, S., 2015. Global Mining Risk Footprint of Critical Metals Necessary for Low-Carbon Technologies: The Case of Neodymium, Cobalt, and Platinum in Japan. Environ. Sci. Technol. 49, 150205140934001. doi:10.1021/ es504255r

Nassar, N.T., Graedel, T.E., Harper, E.M., 2015. By-product metals are technologically essential but have problematic supply. Sci. Adv. 1, e1400180. doi:10.1126/sciadv.1400180

Park, S.-J., Heo, G.-Y., 2015. Precursors and Manufacturing of Carbon Fibers, in: Park, S.-J. (Ed.), Carbon Fibers. Springer. doi:10.1007/978-94-017-9478-7_2

PCl, 2013. Acrylonitrile and Derivatives - Monthly Report September 2013.

plastemart, 2014. 50 percent increase in global propylene productiony by 2030 leads to shift in historical supply relationships [WWW Document]. URL http://www.plastemart.com/PlasticTechnical-Article.asp?LiteratureID=2163\&Paper=Increase-in-global-propylene-productionradical-shift-in-historical-supply-relationships (accessed 6.30.15).

Schaffartzik, A., Mayer, A., Gingrich, S., Eisenmenger, N., Loy, C., Krausmann, F., 2014. The global metabolic transition: Regional patterns and trends of global material flows, 1950-2010. Glob. Environ. Chang. 26, 87-97. doi:10.1016/j.gloenvcha.2014.03.013

Schneider, L., 2014. A comprehensive approach to model abiotic resource provision capbility in the context of sustainable development. Fak. III Prozesswissenschaften. Technische Universität Berlin, Berlin.

Schneider, L., Berger, M., Schüler-Hainsch, E., Knöfel, S., Ruhland, K., Mosig, J., Bach, V., Finkbeiner, M., 2014. The economic resource scarcity potential (ESP) for evaluating resource use based on life cycle assessment. Int. J. Life Cycle Assess. 19, 601-610.

Smith, R., Adibi, S., Khimasia, S., 2012. 2012 petrochemical outlook: Middle East [WWW Document]. URL http://www.hydrocarbonprocessing.com/Article/3017586/2012-petrochemical-outlookMiddle-East.html (accessed 6.30.15).

Sonnemann, G., Gemechu, E.D., Adibi, N., Bruille, V. De, Bulle, C., 2015. From a critical review to a conceptual framework for integrating the criticality of resources into Life Cycle Sustainability Assessment. J. Clean. Prod. doi:10.1016/j.jclepro.2015.01.082

U.S. Department of Defense, 2013. Strategic and Critical Materials 2013 Report on Stockpile Requirements Office of the Under Secretary of Defense for Acquisition, Technology and Logistics.

U.S. Energy Information Administration, 2015. Refinery Net Production Propylene [WWW Document]. URL http://www.eia.gov/dnav/pet/PET_PNP_REFP2_A_EPLLPY_YPY_MBBL_A.htm (accessed 6.30.15).

U.S. National Research Council, 2008. Minerals, Critical Minerals, and the U.S. Economy. The National Academies Press, Washington, DC. 
UN, 2015. Commodity Trade Statistics Database [WWW Document]. URL http://comtrade. un.org/db/default.aspx

Vieira, M., Ponsioen, T., Goedkoop, M., Huijbregts, M., 2016. Surplus Cost Potential as a Life Cycle Impact Indicator for Metal Extraction. Resources 5, 2. doi:10.3390/resources5010002 
Postprint

\title{
Extending the geopolitical supply risk indicator: Application of life cycle sustainability assessment to the petrochemical supply chain of polyacrylonitrile-based carbon fibers
}

\author{
Appendix A. Supplementary data \\ Christoph Helbig ${ }^{a}$, Eskinder D. Gemechu ${ }^{\mathrm{b}}$, Baptiste Pillain ${ }^{\mathrm{b}}$, Steven B. Young ${ }^{\mathrm{c}}$, \\ Andrea Thorenz ${ }^{a}$, Axel Tuma ${ }^{a}$, Guido Sonnemann ${ }^{b}$ \\ a: Resource Lab, University of Augsburg, Universitätsstr. 16, 86159 Augsburg, Germany \\ ${ }^{\mathrm{b}}$ : The Life Cycle Group, Institute of Molecular Sciences, Université de Bordeaux, Bordeaux, France \\ ${ }^{c}$ : School of Environment, Enterprise and Development (SEED), University of Waterloo, Waterloo, Canada \\ Helbig C., et al., Extending the geopolitical supply risk indicator: Application of life cycle sustainability \\ assessment to the petrochemical supply chain of polyacrylonitrile-based carbon fibers, Journal of \\ Cleaner Production (2016), available at http://dx.doi.org/10.1016/i.jclepro.2016.07.214
}

Supplementary Material to:

\begin{tabular}{|c|c|c|c|}
\hline Section Topic & Tables & Figures & Page \\
\hline Three-stage supply chain calculation formula & & & S2 \\
\hline All GPSR factors (145 countries) & & S1 & S3 \\
\hline Case study Peru: Petroleum and propene supply chain & & S2 & S4 \\
\hline
\end{tabular}




\section{Three-stage supply chain calculation formula}

In case of a three-stage supply chain (i.e., petroleum-propene-acrylonitrile), the following formula shows the calculation of the Geopolitical Supply Risk factor.

$$
\begin{gathered}
\operatorname{GPSR}_{C B A c}=H H I_{C} * \overline{W G I_{C B A c}}=\sum_{i} \frac{p_{C i}^{2}}{P_{C}^{2}} * \sum_{i} \sum_{k} \sum_{l} g_{i} \frac{f_{C i k}}{p_{C k}+F_{C k}} \frac{f_{B k l}+\delta_{k l} p_{B l}}{p_{B l}+F_{B l}} \frac{f_{A l c}+\delta_{l c} p_{A c}}{p_{A c}+F_{A c}}, \\
\delta_{a b}= \begin{cases}1, & a=b \\
0, & a \neq b\end{cases}
\end{gathered}
$$

Here, GPSR ${ }_{C B A c}$ is the factor for using the product $A$ in country $c$, which is produced in countries $i$, from intermediate products $B$ (produced in countries $k$ and imported to countries $i$ ), which itself is produced from the reactant $C$ (produced in counties $l$ and imported to countries $k$ ). 


\section{All GPSR factors (145 countries)}

Figure S1 shows all calculated Geopolitical Supply Risk characterization factors calculated for 145 different countries.
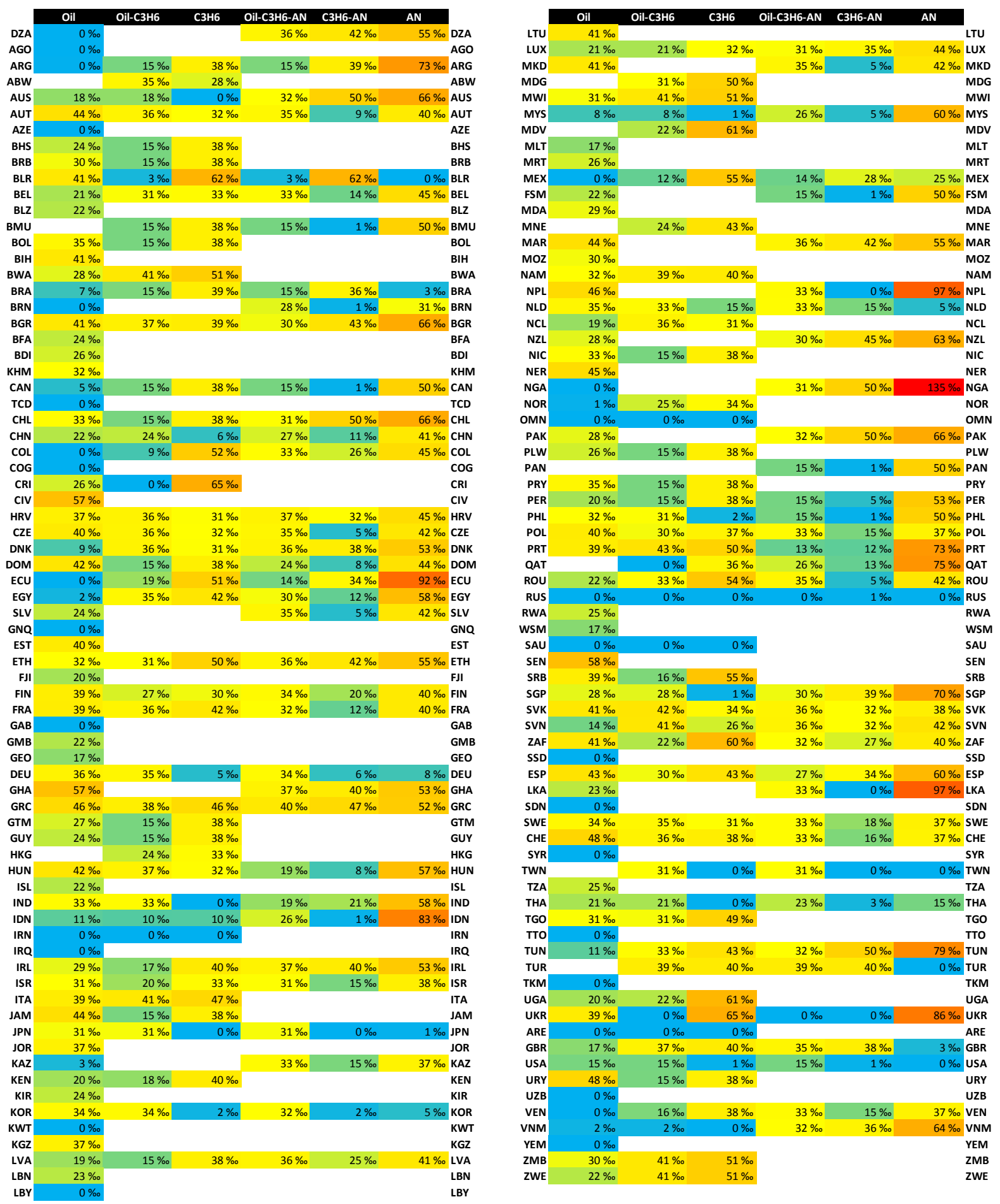

Figure S1: Geopolitical Supply Risk factors for 145 countries in six different supply chain scopes 


\section{Case study Peru: Petroleum and propene supply chain}

Figure S2 shows the simplified patterns for the supply chain of Peru, including the petroleum and propene supply chain (extended Figure 4 from the main article).

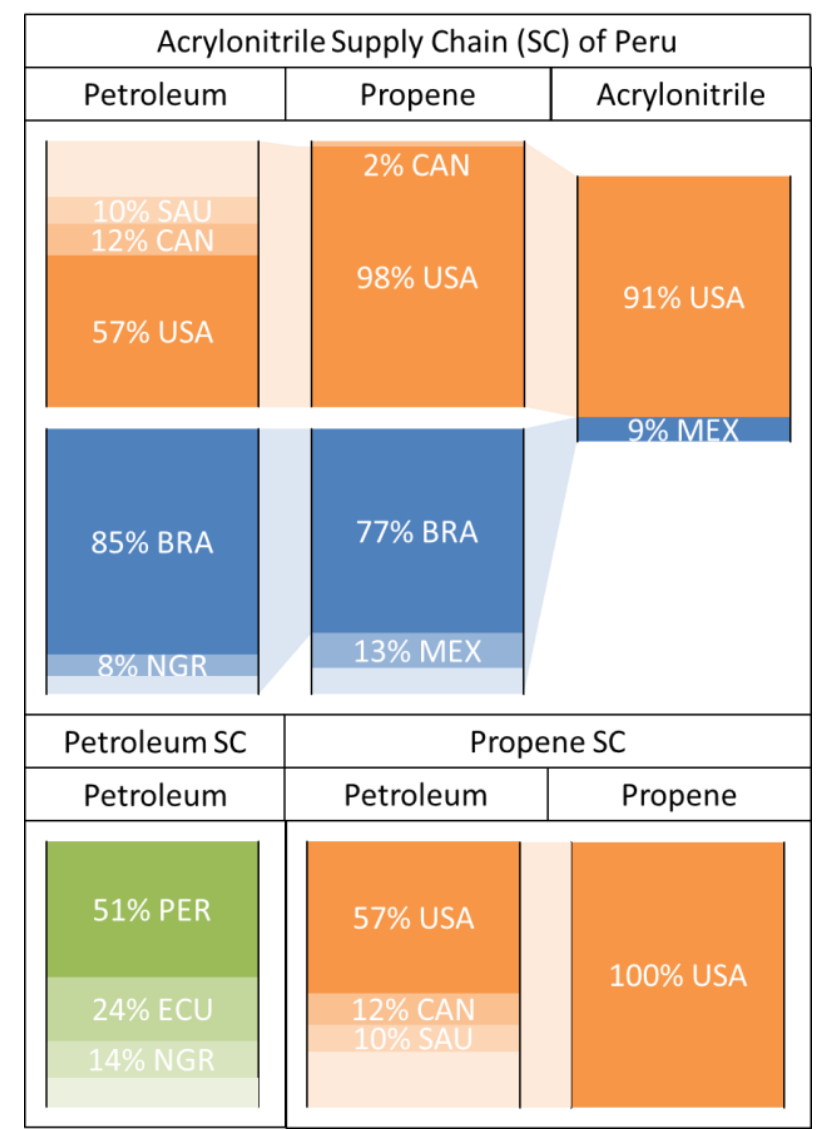

Figure S2: Supply chain patterns of Peru for acrylonitrile, propene and petroleum (only major contributing countries are shown). 